\title{
The syntax and prosody of apposition in Shingazidja*
}

\author{
Kathleen M. O'Connor \\ Cédric Patin \\ University of Lille and CNRS
}

\begin{abstract}
This paper investigates the syntax-prosody interface with respect to apposition in Shingazidja. We examine the syntactic properties of two types of apposition (restrictive and non-restrictive). While restrictive apposition appears to form a single constituent, the syntactic data for non-restrictives are ambiguous between a single constituent analysis and an analysis in which the appositive and its anchor are syntactically separate. Prosodic data confirm the single constituent analysis for restrictive apposition, and provide evidence that non-restrictive appositives are syntactically linked to their antecedent and prosodically embedded in their host clause. The phenomenon of final raising emerges as the principal indicator of intonational phrases in Shingazidja; tone shift signals phonological phrasing. Our analysis is formalised in Optimality Theory through a comparison of Align/Wrap theory and Match theory. A Match-theory account predicts the existence of recursive phonological phrasing, and we present evidence supporting this prediction.
\end{abstract}

\section{Introduction}

Apposition presents a challenge for syntactic analysis, in particular of the structure termed non-restrictive apposition. Specifically, the syntactic behaviour of an appositive and its anchor makes it difficult to determine their relationship. One piece of evidence that is rarely brought to bear on this question comes from the interaction of syntax and prosody. In this paper, we ask what the phonological facts of apposition can tell us about its syntax. Moreover, apposition is rarely examined in less widely studied languages, thus our paper has the added advantage of describing

* E-mail: KATHLEEN.OCONNOR@UNIV-LILle3.Fr, CEDRIC.PATIN@UNIV-LILle3.Fr.

Portions of this article were presented at the Syntax-Phonology Interface Workshop held at the Zentrum für Allgemeine Sprachwissenschaft, Berlin in November 2012. We would like to thank Seunghun Lee for the invitation to participate in this workshop. Another version of the article was presented at Bantu 5 in Paris in June 2013. We are grateful to audiences at both conferences for helpful questions and suggestions. We would also like to thank our two anonymous reviewers, as well as Lisa Selkirk and the editors of Phonology, for their comments, which allowed us to make significant improvements to the paper. 


\section{Kathleen M. O’Connor and Cédric Patin}

a previously unstudied structure in Shingazidja, a Bantu language (G44a) spoken in the Comoros. To our knowledge, this is the first study that focuses specifically on apposition in a Bantu language. ${ }^{1}$

This article has two primary goals. We first examine the syntax of apposition in Shingazidja, and show that the facts concerning prosody can shed light on the syntactic relationship between the host clause and the appositive. Second, we test previous analyses of the prosody-syntax interface in Shingazidja against new apposition data. Our analysis compares the predictions of Align/Wrap theory (Selkirk 1986, 1995, 2000, Truckenbrodt 1999) and Match theory (Selkirk 2009, 2011, Elfner 2012).

The paper is organised as follows. $\$ 2$ gives a brief overview of the phonology of Shingazidja. $\$ 3$ introduces apposition, and establishes the syntactic facts of apposition in Shingazidja. In $\$ 4$ we explore the prosody of apposition with respect to the syntactic data, and $\$ 5$ presents our OT analysis of the syntax-prosody interface alongside our comparison of Align/Wrap theory and Match theory. We conclude in $\$ 6$ with a discussion and directions for further research.

\section{Background on the phonology of Shingazidja}

In this section we provide a short description of the main prosodic parameters of Shingazidja, focusing on the tone rules (tone shift and the deletion of even-numbered surface tones) and the phonological and intonational phrasing parameters. The data were collected in Lille, and come from three native speakers of Shingazidja. Our principal informant is 34 years old, and has lived in France for approximately 10 years. He is a native speaker of the Washili dialect, and was consulted and recorded specifically for this study between July 2012 and July 2014. Two additional speakers were consulted on particular points, but were not recorded.

\subsection{Tone rules}

The major characteristics of the Shingazidja tone system are discussed in Tucker \& Bryan (1970), Philippson (1988, 2005), Cassimjee \& Kisseberth (1989, 1992, 1993, 1998) and Patin (2007, 2010).

A $\mathrm{H}$ tone shifts rightward. It shifts right to the end of a phonological phrase $(\varphi)$, unless it is blocked by a syllable bearing an underlying tone. Syllables associated with an underlying tone are underlined throughout the paper: in the form for 'balloons' in (1a), both stem vowels are underlined, indicating that the word has the underlying form $/$ mi-píra $/ .{ }^{2}$ The shift of the tone leads to the deletion of every even-numbered tone (in accordance with the Obligatory Contour Principle). In (1b), for instance, the

1 Some scholars have discussed the structure in a broader context, e.g. Van de Velde (2013) on the causative construction in Bantu.

2 Shingazidja forms are given in IPA transcription throughout. The voiced palatal approximant is represented as [j]. Nasals which are not underlyingly specified for place are represented as $\mathrm{N}$. 
tone of the noun /ma-ßáha/ shifts to the penult of the adjective/ma-ilí/, and the tone of the adjective is thus deleted. ${ }^{3}$ In (1c), however, the tone of the adjective surfaces because the tone of the noun has been deleted by the tone of /tsi-wóna/. ${ }^{4}$

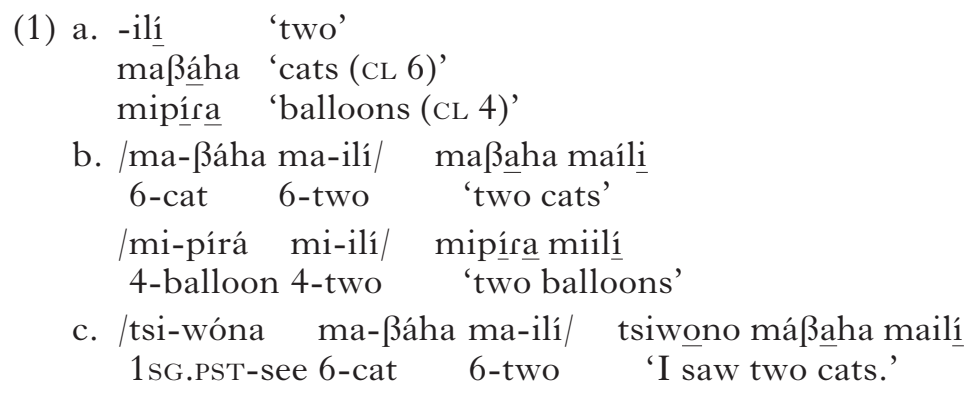

Tone is not bounded by the edges of the prosodic word $(\omega)$. In (1), for instance, the tones of the nouns and/or verbs are free to move to the following word(s). More precisely, the tone shifts as far as possible toward the end of a phrase, as shown in (2), where the tone of /ha-wóno/ shifts through $/ \mathrm{n}$-dovu/ to the penultimate syllable of the phrase. ${ }^{5}$
(2)
ha-wóna N-dovu N-bilí/
1.PST-see 10-elephant 10 -two
hawono ndovu mbíli
'He saw two elephants.'

\subsection{Phonological phrases}

The boundaries of phrases interact with tone shift, such that a tone cannot cross the edge of a $\varphi$. In (3), the tone of the subject NP stops on the last syllable of the noun instead of continuing rightward onto the first syllable of /ha-rém-a/.

\section{(3) /mu-limádzi ha-réma $\emptyset$-ßáha/ (mlimądzí) $)_{\varphi}(\text { haremé pạha })_{\varphi}$ 1 -farmer 1.PST-hit 5-cat $\quad *(\text { mlimądzi háreme páha })_{\varphi}$ 'A farmer beat a cat.'}

The distribution of tone shift therefore provides evidence for $\varphi$ edges or boundaries. Based on this evidence, we can for instance conclude that a $\varphi$ boundary separates a dislocated element from its host, or two coordinated elements.

3 In Shingazidja, cardinal numbers (such as /-ilí/ 'two' in (1)) are adjectives.

${ }^{4}$ Numbers refer to noun classes. Other abbreviations used are: $1 \mathrm{SG}=1$ st person singular, $\mathrm{AUG}=$ augment, $\mathrm{OM}=$ object marker, $\mathrm{PASS}=$ passive, $\mathrm{POSS}=$ possessive, $\mathrm{PRN}=$ pronoun, PST $=$ past, REL $=$ relative.

5 Such cases rarely occur at a standard speech rate in the variety of Shingazidja spoken in Moroni, due to eurythmic constraints. 


\section{Kathleen M. O’Connor and Cédric Patin}

The maximal VP and the $\varphi$ domain of tone shift are coextensive. For instance, in (4), from Cassimjee \& Kisseberth (1993), the tone of the verb shifts onto the direct object/ma-pésá/ through the beneficiary /wa-ndu/, indicating that the whole VP forms a single $\varphi$.
(4) /tsi-níka
wa-ñdu ma-pésá/
1SG.PST-give 2-person 6-money
(tsinika wandu mápesá) ${ }_{\varphi}$
'I gave money to people.'

A $\varphi$ boundary is also associated with the 'augment' (whose behaviour is similar to that of the definite article in languages with article systems). In (5b), as opposed to (5a), the tone of the verb cannot shift onto the object, because the object is preceded by an augment (the boundary is optional in the present tense).
a. /ha-níka N-umbá/
1.PST-give 10-house
b. /ha-níka ze=N-umbá/
1.PST-give 10.AUG $=10$-house
(hanika númba $)_{\varphi}$
'He gave houses.'
(haniká) ${ }_{\varphi}\left(\mathrm{ze}=\right.$ numbá $_{\varphi}$
'He gave the houses.'

The boundary precedes the augment when it cliticises to a following noun in formal speech (5b), and follows the augment when it cliticises to a preceding element (cf. (32) below) in casual speech.

\subsection{Intonational phrases}

In (6), the underlying tone stays on the penultimate syllable of the sentence, rather than shifting to the last syllable. Moreover, a tone that shifts rightward from a preceding syllable also stops on the penult, rather than continuing to the final syllable (cf. (28)).

(6) $/$ ze $=$ N-búda pía za-vundzíha/

10.AUG $=10$-stick all 10.REL.PST-break

$(z e=\text { mbu ú pía zavundzíha })_{\varphi}$

'all the sticks that broke'

The fact that a tone cannot shift to the last syllable of the utterance is sometimes called 'extraprosodicity' (cf. Odden 1990). The term is, however, unsatisfactory, since a 'lexical' tone can appear on the last syllable of an utterance - e.g. (4) and (5b).

This non-finality effect is cited as the indicator of an intonational phrase ( $\imath$ ) in Patin $(2007,2010)$, following Cassimjee \& Kisseberth (1998): it would be the result of a right $\imath$ edge coinciding with a right $\varphi$ edge. We discuss the context of non-finality further in $\$ 4$, building upon the results of our investigations of appositives.

\section{Apposition in Shingazidja}

In this section we provide an overview of apposition in Shingazidja. We first explain the two main types, before giving an overview of their 
syntactic behaviour. Our discussion of Shingazidja is supplemented by examples from and discussion of English, for which a large body of research on apposition already exists.

\subsection{Restrictive and non-restrictive apposition}

Apposition can be divided into two types: restrictive (RA) and nonrestrictive (NRA). These two classes parallel the classification of relative clauses, because the two structures are similar in their function (e.g. O'Connor 2008).

In RAs, the apposition limits the possible reference of the head, as in (7), which might be uttered in a context where the participants know two or more distinct people named Juma. /mu-leví/ 'drunkard' allows the interlocutor to identify which Juma the speaker is referring to.

$$
\begin{aligned}
& \text { /dzumwá mu-leví ha-réma Ø-ßáha/ } \\
& \text { Juma 1-drunkard 1.PST-hit 5-cat } \\
& \text { dzumwa mlévi hasemé paha } \\
& \text { 'Juma the drunkard hit a cat.' }
\end{aligned}
$$

The apposition consists of two units, 'Juma' and 'the drunkard', the second of which identifies the first. We refer to the first unit ('Juma') as the anchor and the second ('the drunkard') as the appositive. The term apposition refers to the anchor and appositive together.

In an NRA, for example (8), the appositive adds supplementary information about the anchor, but does not participate in identifying its reference. This is accomplished through other means: it may be the unique member of a class or identifiable from the preceding discourse. (The symbol ' $l$ ' indicates a prosodic boundary, without specifying its type. Its identification will be the focus of subsequent sections.)

$$
\begin{aligned}
& \text { /dzumwá je=mu-leví yga=je dziráni w-a=hángú/ } \\
& \text { Juma 1. } \mathrm{AUG}_{\mathrm{UU}}=1 \text {-drunkard is }=1 \text {. AUG neighbour } 1-\mathrm{of}=1 \text {.POSS } \\
& \text { dz̧umwáa } \mid \text { e=mleví } \mid \text { ng=e dzicani wá=hạggú } \\
& \text { 'Juma, the drunkard, is my neighbour.' }
\end{aligned}
$$

(8) would be used in a context in which the anchor is the unique Juma known to the participants in the discourse or in which the identity of the referent is clear from the preceding discourse.

The differences extend to punctuation, intonation and syntax. In languages with a strong written tradition, such as English, an NRA, but not an RA, is set off from the rest of the clause by punctuation (e.g. Quirk et al. 1985). In spoken language, pauses separate the NRA from the rest of the clause (e.g. Acuña-Fariña 1999). As for RAs, the two parts form one intonation unit, and are thus not separated by a pause (Keizer 2007). In terms of syntax, Burton-Roberts (1975) observes that, 


\section{Kathleen M. O’Connor and Cédric Patin}

for English, RAs generally contain at least one proper noun, which is not the case for NRAs. Furthermore, the anchor and the appositive in a restrictive apposition must both be definite, whereas non-restrictive appositions display all logical combinations of definite and indefinite units.

In Shingazidja RAs, the situation is slightly different. In (9), the NP /mu-leví/ appears without the augment /je/ (\$2). Though the NP resembles an indefinite NP in form, its interpretation is restrictive, according to our informants. The examples also show that the order of the two elements can be reversed. A restrictive apposition with two indefinite NPs is impossible.

$$
\begin{gathered}
\text { /mu-leví dzumwá ha-réma Ø-ßáha/ } \\
\text { 1-drunkard Juma 1.PST-hit 5-cat } \\
\text { mlevi dzúmwa haremé paha } \\
\text { 'The drunkard Juma hit a cat.' }
\end{gathered}
$$

NRAs, on the other hand, behave like English with respect to definiteness and indefiniteness: all combinations are possible, as shown in (10).

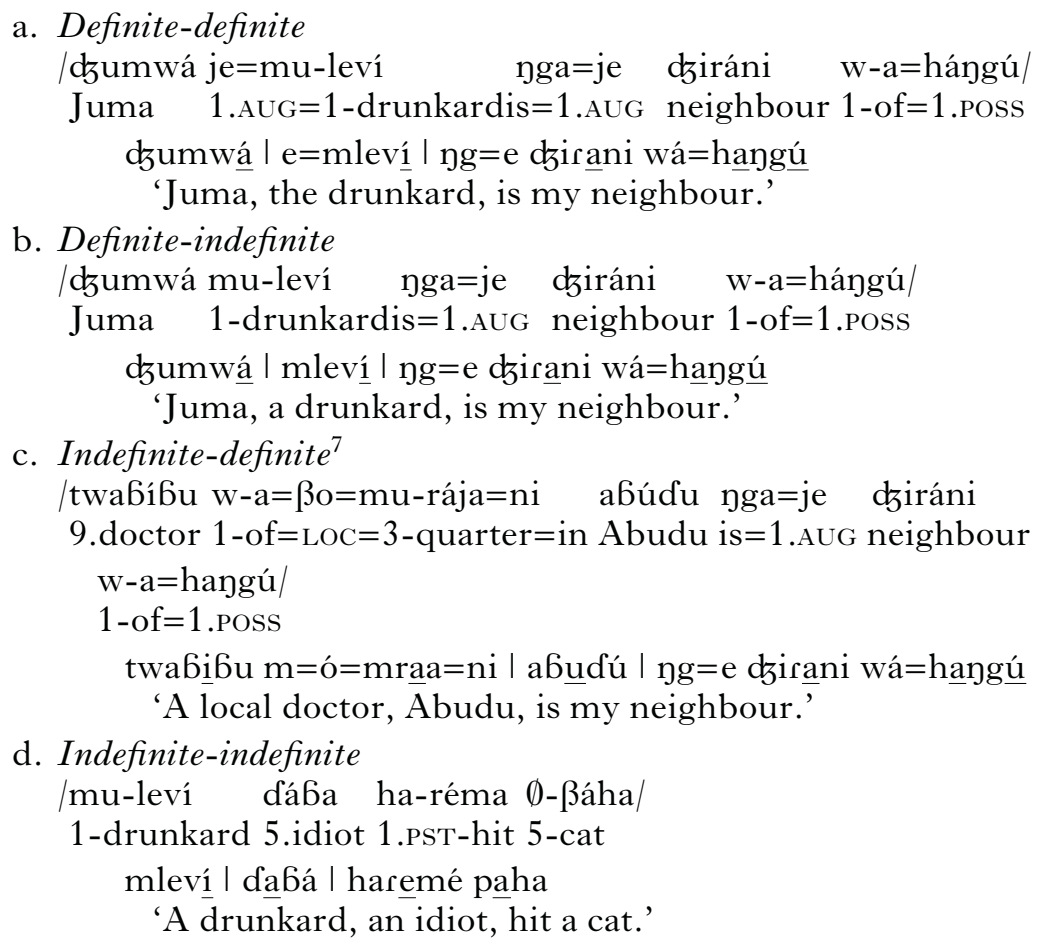

Another characteristic involves stacking: multiple NRAs can be related to a single anchor, whereas this is not possible with RAs. In stacking, each appositive is individually set off from the rest of the sentence. An example is given in (11), where the anchor is followed by two appositives. 
(11) / dzumwá mu-leví dába ha-réma Ø-ßáha/

Juma 1-drunkard 5.idiot 1.PST-hit 5-cat

dzumwáa | mleví | dạbá | haremé pạha

'Juma, a drunkard, an idiot, hit a cat.'

A further question concerns the syntactic category of the apposition. For English, most researchers agree that the anchor is nominal (Quirk et al. 1985, de Vries 2006, O'Connor 2008, Heringa 2011, but cf. e.g. BurtonRoberts 1975). There is less consensus concerning the category of the appositive. For RAs, it seems that the appositive is always an NP, as in (9). For NRAs, some researchers claim that the appositive must be of the same category as the anchor (e.g. de Vries 2006) and thus nominal, while others allow for NRAs that are prepositional or adjectival (Quirk et al. 1985). It is not relevant here to detail the arguments for or against NRAs that are not NPs (see O'Connor 2008 for an overview). However, we assume that appositives can be nominal, prepositional or adjectival. ${ }^{6}$ This is based on Doron (1992), who demonstrates that NRAs display behaviour associated with predicates: they do not allow quantification over individuals (12a), do allow $i$-within- $i$ (12b), may appear without a definite article (12c), may be modified by adverbs that typically modify predicates (12d) and may contain floating quantifiers, which mark collectivity on predicates (12e) (examples from Doron 1992: 30-31 and Quirk et al. 1985: 635).

(12) a. The picture on the wall, a tree/*every tree, was made by Mary.

b. $\mathrm{John}_{i}$, $\left[\text { his }_{i} \text { own worst enemy }\right]_{i}$, lost the election again.

c. George Washington, President of the Union, planted a cherry tree.

d. Norman Jones, then a student, wrote several best sellers.

e. The men, both/all doctors, were awarded medals.

If appositives contain predicates, we can assume that they can contain the non-nominal categories to which predicates belong. Thus we must consider adjectival and prepositional appositives as well as nominal ones.

A further assumption which we make is that appositives are larger than a single constituent, and correspond to a CP. This differs from Doron's (1992) position, which is that appositives consist of a single constituent acting as a predicate. We assume that an appositive is a CP that contains a covert subject as well as the predicate.

As O'Connor (2008) shows, appositives contain a subject that corresponds to the anchor. This is based on evidence that appositives may contain anaphors that have to be bound within the appositive, as in (13).

${ }^{6}$ Non-restrictive modifiers with a verbal head are also possible. We set them aside here: they demand a separate analysis, as they cannot always be straightforwardly equated with a finite clause in the same way as non-verbal NRAs (see O'Connor 2008). 


\section{Kathleen M. O’Connor and Cédric Patin}

(13) Durrell - himself a former diplomat - was born in India. (Guardian, 29/4/02)

The presence of floating quantifiers corresponding to the subject of the predicate, as in (12e), provides further evidence that appositives contain a subject.

The assumption that appositives are CPs is based on several phenomena. First, independent illocutionary force is associated with CP (Rizzi 1997), and appositives appear to have their own illocutionary force (Heringa 2011). ${ }^{7}$ In (14a) the main clause is a polar question (signalled by a superhigh tone "' on the penult), whereas the appositive is asserted. Second, appositives can contain conjunctions, which are located in the CP layer of the clause (14b). Finally, appositives may contain adverbs that are associated with the CP (Potts 2005, Heringa 2011), as in (14c).
a. / dzumwá je=mu-leví
ha-réma Ø-ßáha/
Juma 1.AUG $=1$-drunkard 1.PST-hit 5-cat
dzumwá $\mid \mathrm{e}=$ mleví $\mid$ haremé păha
'Did Juma, the drunkard, hit a cat?'

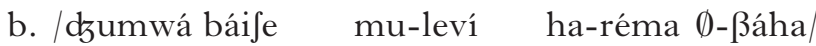
Juma although 1-drunkard 1.PST-hit 5-cat
dzumwáa | baiifé mleví | haremé pạha
'Juma, even though a drunkard, hit a cat.'
c. /dzumwá hakíka mu-leví ha-réma Ø-ßáha/
Juma really 1 -drunkard 1.PST-hit 5-cat
dz̧umwá | hakika mleví | haremé pạha
'Juma, truly a drunkard, hit a cat.'

As well as these differences, NRAs display several other distinct syntactic properties. We will describe these in more detail below as part of our discussion of the main syntactic question related to appositives.

\subsection{The external syntax of appositives}

A key syntactic question about appositives concerns the link between the appositive and clause containing the anchor, or the host clause. In RAs, the link is relatively straightforward and uncontroversial. The behaviour of NRAs, however, raises questions that obscure the nature of the link between the appositive and the host clause.

7 Rizzi (1997) assumes that CP is composed of several functional projections. One of these, ForceP, is associated with illocutionary force. While one could examine the individual projections in Rizzi (1997) to see which are and are not present in appositives (see O'Connor 2008 for an overview), this is beyond the scope of the present paper. We are merely demonstrating here that appositives contain a CP layer of some sort. 
3.2.1 Restrictive appositives. RAs contain two nominal elements. One of these is generally a proper noun. In all cases, both elements have a definite interpretation. Together, the two parts form a prosodic unit (Keizer 2007). Furthermore, the first element cannot be restrictively modified by a prepositional phrase or relative clause (e.g. Acuña-Fariña 1996), as shown in (15) for Shingazidja.

$$
\begin{aligned}
& \text { */mu-leví } \quad \mathrm{w}-\mathrm{a}=\mathrm{ho}=\mathrm{mu}-\mathrm{h} \text { ha dzumwá ha-réma } \emptyset \text {-ßáha/ } \\
& \text { 1-drunkard } 1 \text {-of=17.AUG=3-year Juma 1.PST-hit 5-cat } \\
& \text { mlevi wá=ho=mwaha dzúmwa haremé paha } \\
& \text { 'The drunkard of the year Juma hit a cat.' }
\end{aligned}
$$

Acuña-Fariña (1996) argues on the basis of this that the addition of restrictive information to the anchor makes it difficult to interpret the anchor + appositive as a single unit, because the modified anchor makes the appositive unnecessary for determining reference. Keizer (2007) interprets this to mean that the anchor and the appositive together form a single referential unit.

These facts suggest an analysis in which the RA forms a single NP constituent, which Keizer (2007) calls an extended nominal predicate. Note that Keizer distinguishes several subcategories of RA, which we will set aside for the purposes of the present paper. For all types, she assumes that the two units form a single constituent NP. ${ }^{8}$ Generalising over Keizer's types, we have the structure in (16).

$$
[[\mathrm{N}][\mathrm{N}]]_{\mathrm{NP}}
$$

3.2.2 Non-restrictive appositives. Far more attention has been paid to NRAs than to RAs, because NRAs display syntactic characteristics that make it difficult to analyse the relationship between the appositive and its host clause. In this section, we discuss these different characteristics, and then provide a summary of the two major approaches to accounting for the relationship: 'orphanage' and 'integration'. This parallels the issues surrounding the attachment of non-restrictive relative clauses to their host clause. In fact, many accounts developed for non-restrictive relatives can be applied to appositives on the basis of the frequently noted resemblance between the two structures (see O'Connor 2008 for discussion). In some analyses (e.g. McCawley 1995), an appositive is derived from a non-restrictive relative clause. In others (e.g. de Vries 2006), a non-restrictive relative is derived from an appositive followed by a restrictive relative clause.

Put simply, proponents of orphanage suggest that there is no syntactic link between the appositive and its host clause, whereas proponents of integration suggest that there is such a link. The two camps consider

8 Keizer (2007) is not working within a generative paradigm and thus does not use the term DP. It would of course be possible to replace her NP with DP here. 


\section{Kathleen M. O’Connor and Cédric Patin}

different syntactic phenomena in support of their approach. We review these characteristics below, and discuss representative orphanage and integration analyses.

There are three phenomena which support an orphanage analysis: extraposition, binding and scope of negation. First, appositives can undergo extraposition, meaning they can be separated from their anchor by another element. In (17), the anchor /abúdu/ is separated from the appositive /twa6íbu w-a $=\beta 0=$ mu-rája $=$ ni/ 'a local doctor' by / dzána/ 'yesterday'.

$$
\begin{aligned}
& \text { /tsi-wóna abúdu dzána twabíbu w-a }=\beta 0=\text { mu-rája }=n i / \\
& \text { 1sG.PST-see Abudu yesterday 9. doctor } 1-\mathrm{of}=\mathrm{LOC}=3 \text {-quarter }=\text { in } \\
& \text { tsiwono ábưứ dzaná } \mid \text { twabibu } \mathrm{m}=\hat{o}=\mathrm{mraa}=\mathrm{ni} \\
& \text { 'I saw Abudu yesterday, a local doctor.' }
\end{aligned}
$$

Extraposition is evidence against a syntactic link, since an integration account must explain how /dzána/ can intervene between the two elements if they form a single constituent.

With respect to binding, a quantifier in the host clause cannot bind a variable in the appositive. This is shown in (18a) for English, where every cannot bind the variable his in the appositive.

(18) I spoke to all the students.

a. *Every student, proud of his achievements, had received an award.

b. Every student proud of his achievements had received an award.

This is evidence against a syntactic link, since there is no other reason for the failure of the quantifier to bind into the appositive, as can be seen when comparing (18a) to (18b). In (18b), the quantifier every can bind his in the complement to the adjective proud when the AP is not part of an appositive. When our Shingazidja informant was asked to construct a sentence similar to (18a), he could not do so, and instead transformed the appositive into a finite relative clause. Binding into the appositive is thus not possible in Shingazidja either.

Negation in the host clause does not negate the appositive. In (19), although the host clause is negated, the appositive is still asserted.

$$
\begin{aligned}
& \text { /ndza-wóna dzumwá je=mu-leví/ } \\
& \text { 1sG.PST.NEG-see Juma 1.AUG }=1 \text {-drunkard } \\
& \text { ndz̧aoná dzumwá | e=mleví } \\
& \text { 'I didn't see Juma, the drunkard.' }
\end{aligned}
$$

Together, these characteristics argue against a syntactic link between the appositive and the host clause. However, two further characteristics do suggest the existence of a link. The first is that the appositive tends to follow the anchor and is interpreted as modifying it, while the second 
characteristic relates to movement. In English, if the antecedent moves for purposes of topicalisation, the appositive moves with it, providing evidence that the two form a single constituent.

(20) a. $\operatorname{Sandy}_{i}$, my best friend ${ }_{i}$, I'm sure you remember.

b. * ${ }^{*} \mathrm{Sandy}_{i}, \mathrm{I}$ 'm sure you remember, my best friend ${ }_{i}$.

NRAs in Shingazidja appear at first to differ from English with respect to topicalisation. In Shingazidja, the entire apposition can be topicalised, as in (21a), just like (20a) for English. However, it is also possible to move the anchor and leave the appositive behind (21b). One potential explanation for this is the presence of the object marker $/ \mathrm{mu} /$, which also refers to 'Juma'. The speaker likely relates the appositive/mu-leví/ to this object marker, rather than to the topicalised anchor, which would explain the contrast between English and Shingazidja. In any case, however, our informant reports a preference for examples like (21a), where the two elements move together.

$$
\begin{aligned}
& \text { a. /dzumwá mu-leví tsi-mu-wóna dzána/ } \\
& \text { Juma 1-drunkard 1sG.PST-1.OM-see yesterday } \\
& \text { dzumwá | mleví | tsimmonó dzạa } \\
& \text { 'Juma, a drunkard, I saw him yesterday.' } \\
& \text { b. /dzumwá tsi-mu-wóna dzána mu-leví } \\
& \text { Juma 1sG.PST-1.OM-see yesterday 1-drunkard } \\
& \text { ho=mu-d } \xi^{1}=\text { ni } / \\
& \text { 17. } \mathrm{AUG}=3-\text { village }=\text { in } \\
& \text { dzumwáa } \mid \text { tsimmono dzaná } \mid \text { mleví } \mid \text { ho=mdz̧í=ni } \\
& \text { 'Juma, I saw him yesterday, a drunkard, in the village.' }
\end{aligned}
$$

Other characteristics relate to phenomena in other languages, but are not relevant for Shingazidja. For example, in some languages with morphophonological case, the anchor and the appositive share the same case (de Vries 2006), though not always (Heringa 2011).

This completes our look at the characteristics used to defend the presence or absence of a syntactic link in apposition. We now turn to a discussion of the different analyses of non-restrictive modification in more detail. A more extensive overview can be found in O'Connor (2008).

In orphanage analyses (e.g. Del Gobbo 2003), the non-restrictive element is generated independently of the anchor in the host clause. In some accounts, the appositive is never syntactically linked to the host clause; the link is established in the discourse. In other accounts, the non-restrictive undergoes a process of attachment during the derivation. For example, Ross (1967) assumes that the host clause and a non-restrictive relative are initially generated independently, as main clauses that are 


\section{Kathleen M. O’Connor and Cédric Patin}

coordinated with one another. The clause of the non-restrictive is then transformed into a relative clause and moved to a position following its antecedent.

Proponents of integration assume that the anchor and the non-restrictive form a single constituent. However, as we have seen, some characteristics argue against this hypothesis. The challenge is to devise a syntactic configuration that allows for a syntactic link without the non-restrictive being within the scope of the host clause.

Several approaches have considered the level of attachment of the nonrestrictive. Toribio (1992) proposes an analysis in which a relative clause is adjoined to the DP of the antecedent. In other approaches, involving 'promotion', the non-restrictive is generated as part of the antecedent/anchor, and then moved outside its scope (see e.g. Kayne 1994).

Other analyses reflect the resemblance between coordination and the anchor-appositive relationship (e.g. de Vries 2006, Heringa 2011). This resemblance is based primarily on the fact that an appositive in English can be introduced by markers such as and and or (Quirk et al. 1985).

A representative example of a coordination approach is found in de Vries (2006), who claims that apposition is a special kind of coordination ('specifying'), in which the appositive provides more specific information about the anchor. He posits the existence of a functional head, \&:P, which hosts the DP of the anchor in the specifier and the appositive in its complement position. The head may be empty, or contain one of the aforementioned apposition markers. This structure, given in (22), allows for a syntactic link between the two elements, but the appositive is nevertheless outside the scope of the anchor.

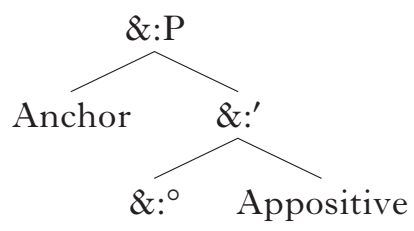

This structure is seen in the example in (23).

$\left[\left[[\text { dzumwá }]_{\mathrm{NP}}\left[[e]_{\&:}[\text { mleví1 }]_{\mathrm{CP}}\right]_{\&::}\right]_{\&: P}\left[\text { haremé }[p \underline{a h a}]_{\mathrm{NP}}\right]_{\mathrm{VP}}\right]_{\mathrm{IP}}$ 'Juma, a drunkard, an idiot, hit a cat.'

It is this account that we adopt as a working hypothesis for the purposes of this paper. We emphasise, however, that it is not possible to clearly determine which of the above proposals best accounts for the data on the basis of the syntactic facts alone. Below, we will draw on prosodic evidence to shed light on this question. 


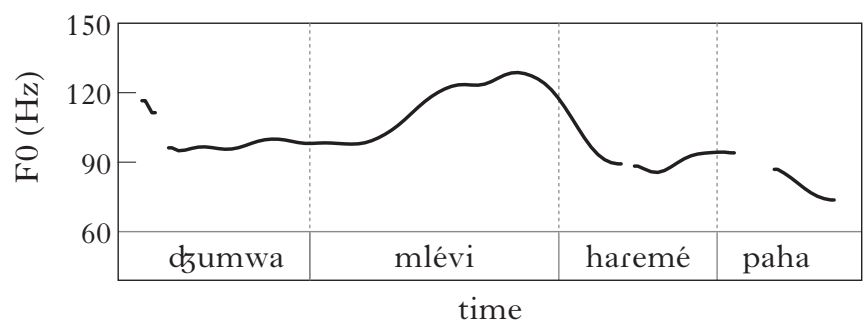

Figure 1

F0 contour for the sentence in (7). The F0 is smoothed (bandwidth $=10 \mathrm{~Hz}$ ) in this and all subsequent figures.

\section{The prosody of apposition}

We now present our data on the prosody of apposition in Shingazidja. We first examine RAs, and demonstrate that the anchor and RA do not occur in distinct domains for tone shift. In $\$ 4.2$, we turn to NRAs, which do display a boundary between the anchor and the appositive. Specifically, we show that NRAs are surrounded by $\imath$ boundaries. We then show that final raising, rather than non-finality, is the marker of the right edge of a non-final $l$. Finally, we propose a recursive $t$ structure for apposition, as shown by the fact that the $l$ of the NRA in the apposition structure is not preceded by an $\imath$-i.e. ${ }^{*}(\ldots \text { Anchor })_{l}(\mathrm{NRA})_{l}$. This recursivity serves as evidence for the integration analysis of the syntax given in (22).

\subsection{Restrictive apposition}

In RAs, the anchor is not separated from the appositive by a prosodic boundary. Evidence for this comes from tone shift: the tone of the anchor can shift to the appositive, as in (7), whose F0 contour is shown in Fig. 1. The tone of /dzumwá/ shifts rightward to /mu-leví/, indicating that the anchor and the appositive form a single phrase within the $\varphi$ domain relevant to tone shift.

This grouping of anchor and RA is consistent with what we see in other languages $(\$ 3)$, and with the prosodic patterns of similar structures in Shingazidja (e.g. the dependent of a genitive construction phrases with its head). Since apposition and relative clauses are similar, it is interesting to note that the prosodic structure of RAs resembles the phrasing of a restrictive relative (see Patin 2010: 199).

The anchor + RA structure is neither preceded nor followed by a mandatory $\varphi$ boundary, as shown in (24).

$$
\begin{aligned}
& \text { /tsi-níka dzumwá mu-leví N-umbá/ } \\
& \text { 1sG.PST-give Juma 1-drunkard 10-house } \\
& \text { tsinika dzúmwa mlevi númbạ } \\
& \text { 'I gave Juma the drunkard a house.' }
\end{aligned}
$$




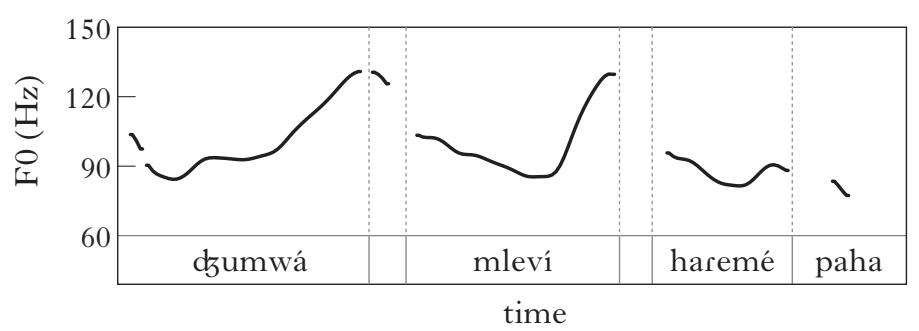

Figure 2

$\mathrm{F} 0$ contour for the sentence in (25).

The tone of /tsi-níka/ shifts to the penult of /dzumwá/, showing that the apposition structure is not preceded by a prosodic break. Additionally, the tone of /mu-leví/ shifts to /N-umbá/, demonstrating that the apposition, like any other NP placed between a verb and its direct complement (cf. (4)), is not followed by a boundary.

In sum, RAs do not have a tone-shift blocking prosodic structure. With respect to prosodic phrasing, an RA exhibits the same behaviour as any other NP. These results are thus consistent with the syntactic facts in $\S 3$ : the anchor and the appositive form a single constituent, namely an extended NP (Keizer 2007). The lack of a prosodic break between anchor and appositive, together with the resemblance between restrictive apposition and other nouns followed by complements, confirms this analysis. We give a formal OT analysis in \$5.1, after we have considered the data for NRAs.

\subsection{Non-restrictive apposition}

4.2.1 Separate phrasing. NRAs have a more complex prosodic structure than RAs. For expositional reasons, we begin by using the notation 'l' to indicate the limits of tone-shift domains, without yet committing to a full prosodic structure analysis. In NRAs, a prosodic break separates the anchor from the appositive, as illustrated in (25) and Fig. 2.

$$
\begin{gathered}
\text { /dzumwá mu-leví ha-réma Ø-ßáha/ } \\
\text { Juma 1-drunkard 1.PST-hit 5-cat } \\
\text { dzumwá I mleví I haremé paha } \\
\text { 'Juma, a drunkard, hit a cat.' } \\
\text { \#‘Juma the drunkard hit a cat.' }
\end{gathered}
$$

In (25), the tone of /dzumwá/ does not shift to /mu-leví/, contrary to what is observed between anchor and RAs (compare Figs 1 and 2). This indicates that the anchor is separated from the appositive by a prosodic boundary, whose precise nature is discussed in $\$ 4.2$. 
As is the case in various other languages (see $\$ 3$ ), NRAs are frequently set off by pauses, as indicated in Fig. 2. However, pausing before, or both before and after, an NRA is not obligatory, especially at a normal to high speech rate.

The NRA is also followed by a tone-shift boundary, as shown in (26). Unlike in (24), the tone of /mu-leví/ cannot shift rightward to the object /N-umbá/, demonstrating that the NRA phrases separately from what follows.

$$
\begin{aligned}
& \text { /tsi-níka dzumwá mu-leví N-umbá/ } \\
& \text { 1sG.PST-give Juma 1-drunkard 10-house } \\
& \text { tsinika dzúmwá | mleví | num6á } \\
& \text { 'I gave Juma, the drunkard, a house.' }
\end{aligned}
$$

(26) also demonstrates that the anchor of an NRA is not preceded by a tone-shift boundary, mirroring the behaviour of verb before object discussed in $\$ 3$.

To summarise, we have shown that the NRA itself is preceded and followed by tone-shift blocking boundaries, and generally by pauses. We now turn to the nature of these boundaries.

4.2.2 Non-restrictive appositives and intonational phrase boundaries. Recall that NRAs are associated with $l$ boundaries in other languages. Furthermore, as mentioned in $\$ 2$, non-finality, i.e. the fact that a tone cannot shift to the last syllable of the utterance, is said to indicate intonational phrasing. Non-finality should thus apply at the end of an NRA. Below, however, we will see that non-finality is confined to the right edge of the sentence, and that a final raising phenomenon provides evidence for the right edge of any non-final $t$ in the sentence, including the $\imath$ associated with an NRA. In the following examples, we will show that the I markers that flank the NRA mark the positions of the left and right edges of an $l$ corresponding to the NRA.

(27) demonstrates that non-finality does not apply at the right edge of an NRA (a) or a non-restrictive relative (b). ${ }^{9}$

(27) a. /dzumwá mu-limádzi ha-réma Ø-ßáha/ Juma 1-farmer 1.PST-hit 5-cat

dzumwá | mlimadź́ | hasemé paha

??dzumwá mlimádzi hasemé paha 'Juma, a farmer, hit a cat.'

b. /dzumwá haßáha ja-tsó-ná házi ha-réma $\emptyset$-ßáha/ Juma now 1.REL.PST-NEG-have job 1.PST-hit 5-cat

dzumwá | haßá atsóna hạzí I haremé pạha

'Juma, at this time without work, hit a cat.'

${ }^{9}$ Extraprosodicity may apply if the NRA is in contrastive focus. We will not explore such cases in this paper. 


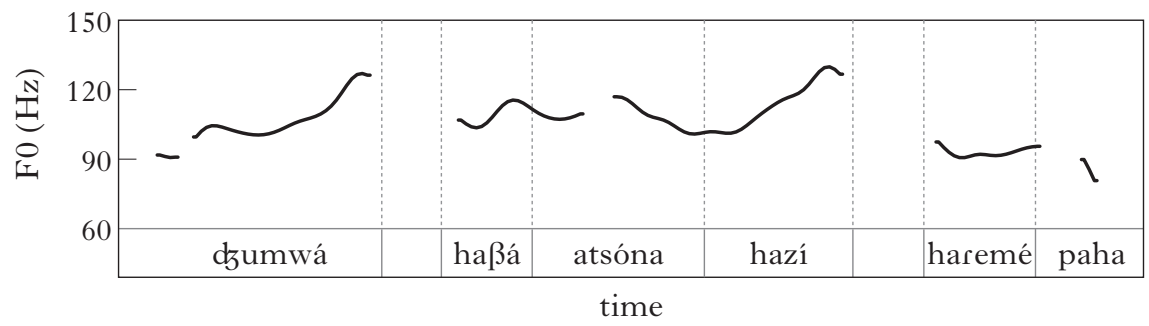

Figure 3

$\mathrm{F} 0$ contour for the sentence in $(27 \mathrm{~b})$.

In (27b) (cf. Fig. 3), the tone of /házi/ shifts to its final syllable, indicating that non-finality does not apply. Since non-finality does not apply at the end of an NRA, and is supposedly the main indicator of $t$ boundaries (Cassimjee \& Kisseberth 1998, Patin 2007), we might conclude that the NRA is followed by a $\varphi$ boundary.

However, this raises various questions. First, it fails to explain why the NRA is regularly bounded by pauses. Pauses, which are typologically associated with $\imath$ boundaries, may also appear in Shingazidja before or after a $\varphi$, e.g. between a subject NP and a VP. This is rarely the case in spontaneous speech, though, whereas pauses before and after the NRA often surface. Second, the syntactic structure in $\$ 3$ predicts that the NRA, as a CP, will constitute an $l$, as CPs are cross-linguistically associated with $\imath$ boundaries. For example, in certain Bantu languages, non-restrictive relatives are associated with $t$ boundaries (e.g. Zulu; Cheng \& Downing 2007).

Furthermore, in other contexts where an $\imath$ boundary is expected, nonfinality does not obligatorily apply at the end of a clause. This occurs with the first of two coordinated clauses, as in (28). Here, the tone of /jémbe/ shifts to the final syllable of the clause, whereas a non-finality effect would be expected (see $\$ 4.2$ for further discussion of this example).

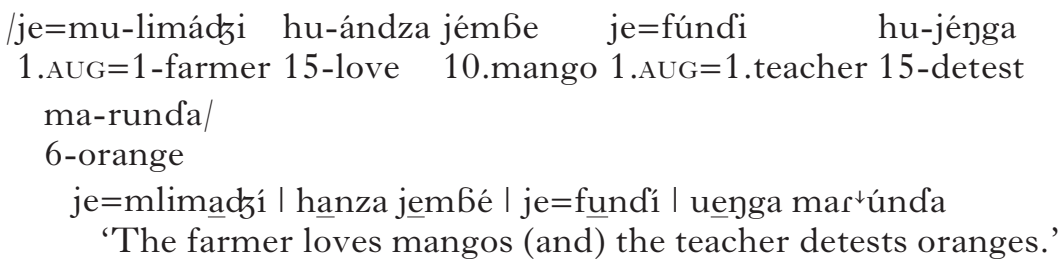

In addition, Patin (2010: 204) provides an example of a non-restrictive relative that does not involve a non-finality effect.

Taken together, these issues lead us (i) to put forward the hypothesis that the boundaries around the NRA are indeed $l$ boundaries, and thus (ii) to call into question analyses in which non-finality is the key to intonational phrasing. 


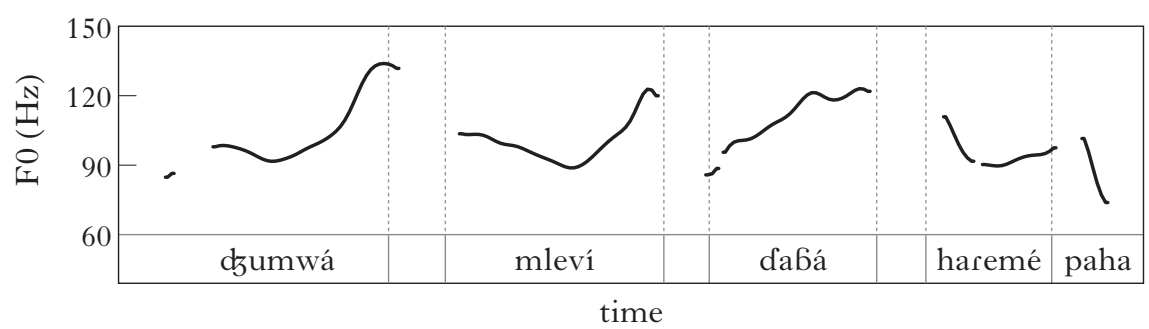

Figure 4

F0 contour for the sentence in (11).

Our research has uncovered an alternative indicator of the right edge of a (non-final) $t$ : final raising. We define final raising as raising of the $\mathrm{F} 0$ on the final syllable of a non-final $l$ to a height that is equal to or greater than the F0 peak that characterises the final tone of a preceding prosodic phrase (in this sense, final raising differs from a suspension of downstep). ${ }^{10} \mathrm{We}$ consider final raising to be the equivalent of the boundary tone $\mathrm{H} \%$ in the ToBI autosegmental-metrical framework (e.g. Beckman \& Pierrehumbert 1986). As we will see below, the F0 peak corresponding to final raising at the right edge of an $l$ is considerably higher than wordfinal F0 peaks found in other contexts. This is perhaps due to phonetic upstepping of the $\mathrm{H} \%$ at the right edge of the $t$.

This final-raising $\mathrm{H} \%$ boundary is seen in Fig. 3, for example, corresponding to (27b). There is a significant $\mathrm{F} 0$ peak at the right edge of /házi/, which is final in the sentence-medial non-restrictive relative. We suggest that (27b) has the (partial) prosodic structure in (29).

(29) dzumwá (haßá atsóna hazí) ${ }_{l}$ haremé pạha

Support comes from a comparison of tone shift and downstep in sentences like $(27 \mathrm{~b})$ with sentences involving stacked appositives, such as (11) (cf. Fig. 4). In (27b), /haßáha/ is followed by a $\varphi$ boundary, indicated by the fact that its tone does not shift to /ja-tsó-ná/. However, the height of its tone is significantly lower than those of the anchor to the left and of the appositive to the right, as shown in Fig. 3. If the appositive were followed by a $\varphi$ boundary, the tone on /házi/ should be downstepped with respect to the tone on /haßaha/, but it is clearly higher.

By contrast, Fig. 4 shows that the tones of the stacked appositives in (11) are all raised to the height of the $\mathrm{F} 0$ at the end of the preceding prosodic phrase, while the tone of /ha-rém-a/ is downstepped. We take this as evidence that the boundaries following the NRAs in (11) are of a different type from those that follow prosodic words when no NRAs are involved. In other words, each individual NRA forms an $t$.

${ }^{10}$ We discuss final $i$ 's below. 


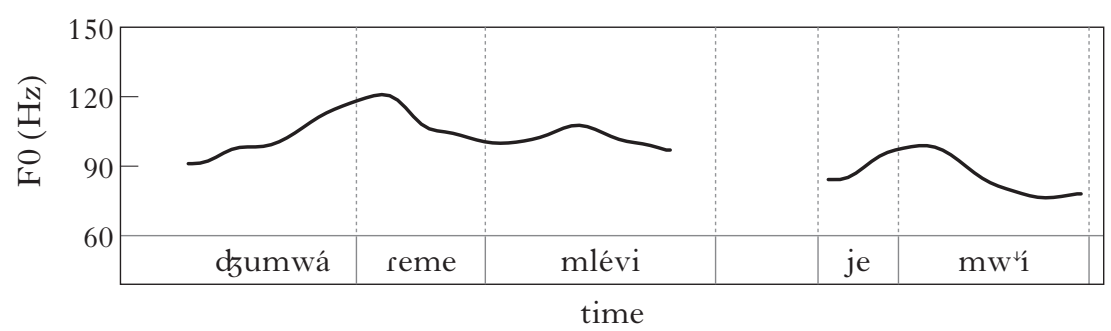

Figure 5

$\mathrm{F} 0$ contour for the sentence in (30).

Independent support for this comes from Patin (2010: 204). In his study of relative clauses in Shingazidja, he provides an F0 contour showing that the end of a non-restrictive relative is also characterised by final raising. Given the similarities observed between non-restrictive relatives and non-restrictive appositives, the data on relatives provide converging evidence for the significance of final raising.

In phrase-final position, the final syllable of the NRA is not associated with final raising (see (30) and Fig. 5). We consider this to be evidence that the raising that characterises non-final NRAs is not a tonal morpheme that signals NRAs.

$$
\begin{aligned}
& \text { /dzumwá ha-réma mu-leví je=mu-wí/ } \\
& \text { Juma 1.PST-hit 1-drunkard 1.AUG=1-bad } \\
& \text { dzumwáa } \mid \text { reme mlévi } \mid \text { je }=\mathrm{mw}^{\downarrow} \underline{\text { í }} \\
& \text { 'Juma hit a drunkard } i \text {, that bad guy }{ }_{i} \text { ' }
\end{aligned}
$$

We have seen that final raising, rather than non-finality, is the clue to intonational phrasing, with pauses providing secondary evidence. We thus propose that NRAs are associated with $l$ boundaries, as expected from cross-linguistic data and our syntactic analysis. We demonstrate below that final raising is also found at the end of non-final clauses that are not NRAs, providing independent evidence for our analysis.

\subsubsection{Independent evidence for final raising as the key to intonational phrase} boundaries. If our claim that final raising, rather than non-finality, provides the best evidence for $i$ 's is correct, final raising should be observed not only at the end of NRAs, but also in any context where the right boundary of an $t$ is expected.

To test this hypothesis, we examined data involving coordinated clauses of the type 'SVO and/but SVO'. Our prediction is that each CP should constitute its own $t$. This receives support from the fact that the first $\mathrm{CP}$ of such utterances in Shingazidja is followed by a spontaneous pause, as illustrated below. 


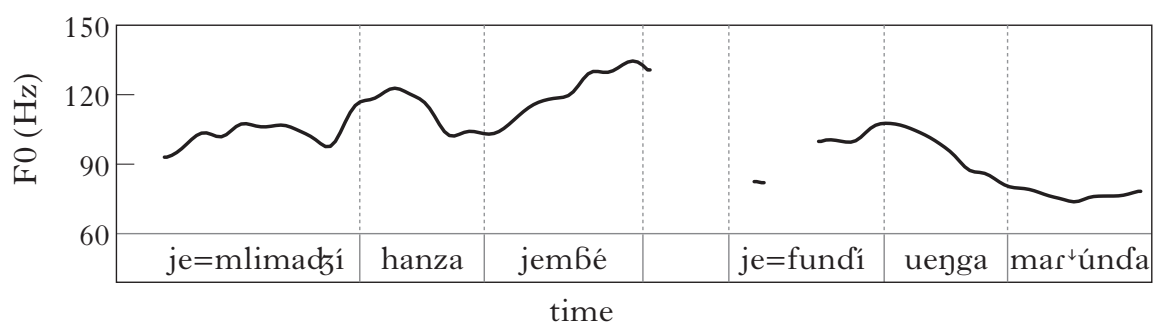

Figure 6

F0 contour for the sentence in (28).

Building on the analysis above, we predict final raising, but not nonfinality, to occur at the end of the first clause, i.e. at the end of the first $t$. We saw in (28) that non-finality does not apply in such situations. What about final raising? Consider Fig. 6, which gives the F0 contour for (28). The tone of /hu-ándza/ is deleted by the tone of the subject (the optional deletion of a tone across $\varphi$ boundaries is described by Cassimjee \& Kisseberth 1993, 1998), and the tone of /jémbe/ is thus free to surface. As expected, the latter tone shifts to the last syllable of the clause, demonstrating that non-finality does not apply. Crucially, Fig. 6 shows that final raising applies at the end of the first clause, since the peak of the F0 contour is associated with the final syllable.

In this section, we have demonstrated that final raising applies not only at the end of NRAs, but also in other syntactic contexts where $\imath$ boundaries are expected. In the following section, we return to the prosody of NRAs. We investigate whether the NRA is prosodically embedded in the matrix clause.

4.2.4 A recursive account. We have claimed that an NRA is followed by an $\imath$ boundary, and we have demonstrated that it is also preceded by a boundary, building on the facts concerning tone shift and the presence of pauses. In sum, the NRA is surrounded by $\imath$ boundaries.

A question which arises is the following: is the $\imath$ of the NRA prosodically embedded in the $t$ of the matrix clause, as in (31a)? Or is the $t$ that corresponds to the NRA prosodically independent, as in $(31 \mathrm{~b})$ ?
(31) a. [host $[\mathrm{NRA}]_{l}$ host $]_{l}$
b. $[\text { host }]_{l}[\mathrm{NRA}]_{l}[\text { host }]_{l}$

We will argue for the structure in (31a). One argument in support of this analysis comes from the fact that, at a normal speech rate, an NRA associated with an object anchor exhibits final raising, while the tone of the anchor does not. For instance, in Fig. 7, corresponding to (32), the tone 


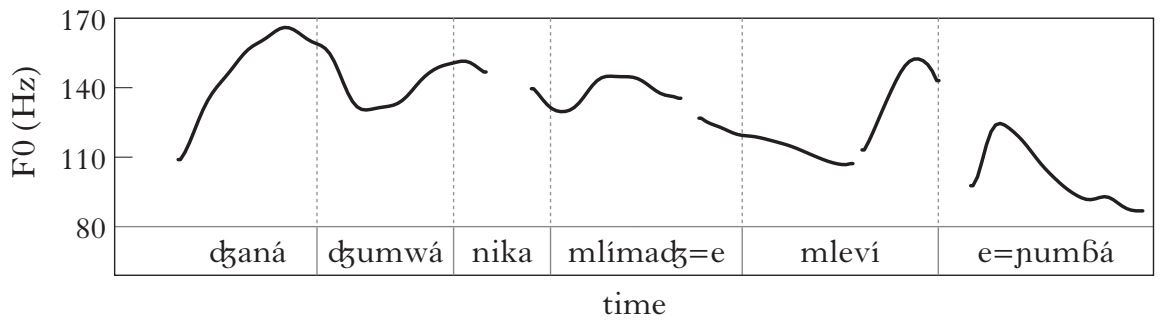

Figure 7

$\mathrm{F} 0$ contour for the sentence in (32).

of the NRA /mu-leví/ is higher than the tone on /mu-limádzi/, indicating that the latter is not followed by an $\imath$ boundary. ${ }^{11}$

(32) / Jána dzumwá ha-níka mu-limádzi=je mu-leví yesterday Juma 1.PST-give 1-farmer=1.AUG 1-drunkard

$\mathrm{e}=\mathrm{N}$-umbá $/$

$\mathrm{AUG}=9$-house

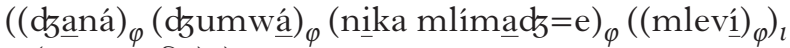
$\left.(\mathrm{e}=\operatorname{numbá})_{\varphi}\right)_{l}$

'Yesterday, Juma gave the house to a farmer ${ }_{i}$, the drunkard ${ }_{i}$.'

Another argument comes from sentences such as (33), where the NRA relates to a subject anchor. As seen in Fig. 8, the tone of the anchor /dzumwá/ is lower than those of the initial adverb on its left and the NRA on its right.

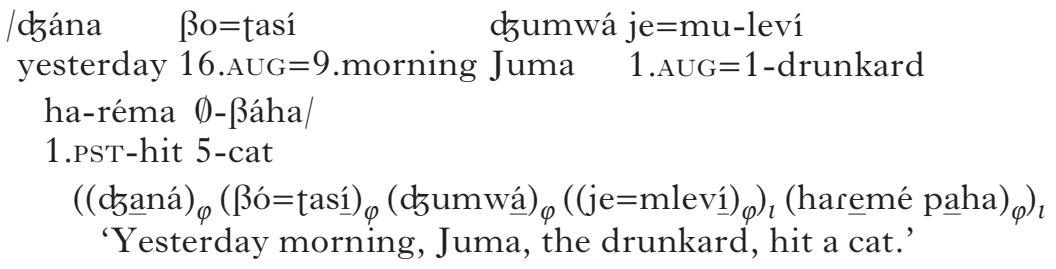

The anchor /dzumwá/ does not display final raising, indicating that it does not appear at the end of an $t$. Compare Fig. 8 with Fig. 4 , where two NRAs are stacked; in the latter case, the tones of both NRAs are raised.

11 In casual speech, the augment cliticises to the preceding element. Due to space restrictions, we cannot address the role of the augment in this paper. 


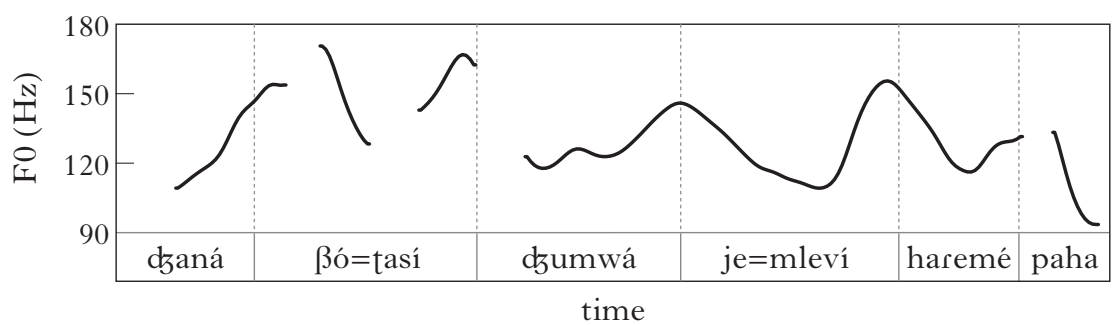

Figure 8

F0 contour for the sentence in (33).

\subsection{Summary}

In this section, we have examined the prosody of apposition in Shingazidja. For RAs, we have shown that the prosodic evidence confirms the single constituent analysis in $\$ 3$. The main evidence is the absence of a prosodic boundary between the appositive and its surrounding elements.

We found that NRAs constitute an $l$, with the left edge of the $l$ at the left edge of the NRA and the right edge of the $r$ at the right edge of the NRA. We then explored the cues for $\imath$ boundaries, and demonstrated that final raising, rather than non-finality, provides the necessary evidence. This was reinforced by evidence that final raising is not unique to NRAs, but occurs at the end of other non-final $l$ 's, such as coordinated clauses. Furthermore, we showed that final raising applies even in the absence of a lexical tone.

Finally, we presented evidence that the NRA is prosodically embedded in its host clause. In terms of syntax, this recursivity provides evidence for an integration analysis. The boundaries and pauses around the NRA show that it is somewhat independent from its host, but at the same time, this recursivity provides evidence for a link between the two elements. This fits best with the integration analyses in $\$ 3$.

\section{An OT analysis of apposition in Shingazidja}

In this section, we present our OT analysis of the syntax-prosody interface of apposition in Shingazidja. In §5.1, we review Patin’s (2007) analysis of phonological phrasing in Shingazidja, and then extend and refine this analysis to account for the apposition data introduced in this paper. The analysis is couched in a theory of the relation between syntactic and prosodic constituency that includes (Edge-based) Alignment (Selkirk 1986, 1995), augmented by the WRAP constraint of Truckenbrodt (1995, 1999), i.e. Align/Wrap theory. In \$5.2, we propose an alternative analysis, which instead assumes the Match theory of the syntax-prosodic 


\section{Kathleen M. O’Connor and Cédric Patin}

constituency relation (Selkirk 2009, 2011, Elfner 2012), and discuss its empirical and theoretical advantages for Shingazidja.

\subsection{Align/Wrap theory}

5.1.1 Background. We begin with a summary of the OT analysis of Shingazidja phonological phrasing developed in Patin (2007), which uses Align/Wrap theory. We then present the approach to basic phrasing within this theory for a case of recursive phrasing involving focus. This serves as a basis for an Align/Wrap-based analysis of RAs and NRAs in §5.1.2 and \$5.1.3.

Align(XP) aligns the right or left edge (depending on the language) of prosodic phrases with the right or left edge of syntactic phrases. Given the Lexical Category Condition (Selkirk 1986, 1995, Truckenbrodt 1999, 2007), only lexical XPs are considered ('constraints relating syntactic and prosodic categories apply to lexical syntactic elements and their projections, but not to functional elements and their projections'; Truckenbrodt 1999: 226).

In Shingazidja, evidence from tone shift shows that the right boundary of a $\varphi$ coincides with the right boundary of a syntactic XPs (recall from $\$ 2$ that verbs and objects are phrased together, while subjects are phrased separately from verbs). This is captured in (34), which is based on Selkirk (1995).

(34) Align-R(XP, $\varphi$ )

Align the right edge of a syntactic XP to the right edge of a prosodic phrase (based on Selkirk 1995).

This constraint must be dominated, however, since two verbal complement NPs are phrased together, as discussed in $\$ 2$ and illustrated in (4). Truckenbrodt $(1995,1999)$ introduces the constraint in (35) to account for similar facts in a number of languages.

\section{(35) WRAPXP}

Each XP is contained in a $\varphi$ (based on Truckenbrodt 1999: 228).

When WrapXP is ranked higher than Align-R(XP, $\varphi$ ), as in Shingazidja, it prevents the insertion of a prosodic boundary inside any maximal XP, as in (36). As a result, the whole VP, or whole NP, will form a single phrase.

\begin{tabular}{|ccc|c|c|}
\hline $\left.\begin{array}{|ccc|c|}\hline \mathrm{X}_{1} & \mathrm{XP}_{2} & \mathrm{XP}_{3}\end{array}\right]_{\mathrm{XP}}$ & WRAPXP $_{\text {R }}$ & ALIGN-R(XP, $\varphi)$ \\
\hline a. ( & )$_{\varphi}($ & )$_{\varphi}$ & $* !$ & \\
\hline b. ( & & )$_{\varphi}$ & & $*$ \\
\hline
\end{tabular}

In (36), candidate (a) satisfies AligN-R(XP, $\varphi$ ), but is rejected because it violates the higher-ranked WRAPXP. To satisfy WraPXP, all words in an 
$\mathrm{XP}$ must be included in a single $\varphi$, as in (b), which is thus optimal, even though it violates Align-R(XP, $\varphi)$.

There is, however, a prosodic configuration that satisfies both ALIGN-R $(\mathrm{XP}, \varphi)$ and WrapXP. Truckenbrodt (1999) proposes the constraint in (37).

\section{(37) Non-Recursivity}

Any two $\varphi$ 's that are not disjoint in extension are identical in extension.

This constraint 'punishes recursive structure to the extent that the two elements of the recursive structure differ in extension' (1999: 240-241). Truckenbrodt shows that the prosodic structure displayed by candidate (38c) will be selected if Non-RECURSIVITY is low-ranked.

\begin{tabular}{|c|c|c|c|c|c|}
\hline & $\mathrm{X} \mathrm{XP}_{2}$ & $\left.\mathrm{XP}_{3}\right]_{\mathrm{XP}_{1}}$ & WRAPXP & Align-R(XP, $\varphi)$ & NON-RECURS \\
\hline a. ( & )$_{\varphi}($ & )$_{\varphi}$ & $* !$ & & \\
\hline b. ( & & )$_{\varphi}$ & & $* !$ & \\
\hline$\leftrightarrow \mathrm{c}$. (( & )$_{\varphi}$ & )$_{\varphi}$ & & & * \\
\hline
\end{tabular}

The recursive structure of (c) does not violate WRAPXP, since the maximal XP $\left(\mathrm{XP}_{1}\right)$ is contained in a single $\varphi$. Nor does it violate AligN$\mathrm{R}(\mathrm{XP}, \varphi)$, since a $\varphi$ boundary follows the embedded XP $\left(\mathrm{XP}_{2}\right)$. However, the evidence from tone-shift patterns in Shingazidja considered above implies the absence of a right edge of a $\varphi$ following $\mathrm{XP}_{2}$.

In order to avoid a recursive structure like (38c) for a VP, NonRECURsivity must dominate Align-R(XP, $\varphi$ ) in Shingazidja, as in (39).

WrapXP, Non-Recursivity $\gg \operatorname{Align-R}(\mathrm{XP}, \varphi)$

The hierarchy in (39) selects the correct output, as illustrated in (40).

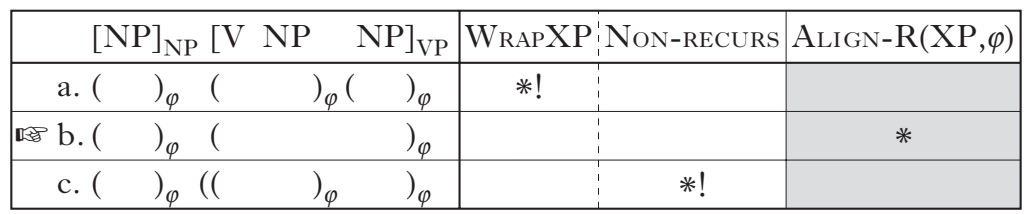

From this preliminary account, it appears that Shingazidja does not exhibit any recursive structures. However, Patin (2007) claims that we do find recursivity in cases of focus.

A focused element is followed by a $\varphi$ boundary in Shingazidja and in other languages. Consider the sentence in (41), where the verb is in narrow focus. 


\section{Kathleen M. O’Connor and Cédric Patin}

(41) /ha-níka mu-leví N-umbá/

1.PST-give 1-drunkard 9-house

haniká I mlevi númba

*haniká I mleví | numbá

'[HE GAVE $]_{\mathrm{FOC}}$ a house to a drunkard.'

The tone of the focused verb does not shift beyond its final syllable to the following word. The effect of focus on the phrasing of Shingazidja is captured in Align/Wrap theory using the constraint in (42), based on Truckenbrodt (1999: 248).

(42) Align-R(Foc, $\varphi$ )

Each focused constituent is right-aligned with a $\varphi$.

WRAPXP is a categorical constraint (Truckenbrodt 1999, SamekLodovici 2005): it can only be violated once, since its effect is neutralised when a maximal XP is split into two different prosodic phrases. Consequently, the boundary after the first object in (41) should be allowed to emerge when WRAPXP is neutralised, as in the OT analysis of Chichewa (Kanerva 1990: 98) in Truckenbrodt (1995: 246) and in (41). However, what is observed in (41) is that the tone of /mu-leví/ shifts to the object /N-umbá/.

To select an output that corresponds to the phrasing structure in (41a), Patin (2007) proposes that NoN-RECURSIVITY is ranked below WRAPXP, as in (43), which incorporates the constraint $*$, 'Avoid $\varphi$ 's altogether', based on Truckenbrodt (1999: 228).

\begin{tabular}{|c|c|c|c|c|c|c|c|c|}
\hline & {$\left[\mathrm{V}_{\mathrm{Foc}}\right.$} & $\mathrm{NP}_{1}$ & $\left.\mathrm{NP}_{2}\right]_{\mathrm{VP}}$ & $\begin{array}{l}\text { AlLIGN-R } \\
(\text { Foc } \varphi)\end{array}$ & $\begin{array}{l}\text { WRAP } \\
\text { XP }\end{array}$ & $\begin{array}{c}\text { NoN- } \\
\text { RECURS }\end{array}$ & $\begin{array}{c}\text { AligN-R } \\
(\mathrm{XP}, \varphi)\end{array}$ & $* \varphi$ \\
\hline a. & & & )$_{\varphi}$ & *! & & & $\mathrm{NP}_{1}$ & * \\
\hline b. & & ( & )$_{\varphi}$ & & VP! & & $\mathrm{NP}_{1}$ & *** \\
\hline c. & & ( & )$_{\varphi}$ & & VP! & & & *** \\
\hline $\log _{\mathrm{g}} \mathrm{d}$ d. ( & & & )$_{\varphi 2}$ & & & $\varphi_{1}$ & $\mathrm{NP}_{1}$ & ** \\
\hline e. $(()$ & & & )$_{\varphi 3}$ & & & $\varphi_{1}, \varphi_{2} !$ & & *** \\
\hline
\end{tabular}

Building on these facts and taking into account the analysis of the prosodic behaviour of the augment, Patin proposes the hierarchy in (44).

(44) Align-R(Foc, $\varphi$ ), WrapXP $\gg$ Non-Recursivity $\gg$ Align-R(XP, $\varphi) \gg * \varphi$

In $§ 5.1$, we test this hierarchy against the apposition data. 
5.1.2 Restrictive apposition. We will first apply the hierarchy in (44) to the data on RAs from $\$ 4.1$, and show that the analysis in $\$ 5.1$ accounts for the data.

Recall from $\S 3$ and $\S 4$ that an RA is an NP, and, furthermore, that the anchor is not separated from the appositive by an XP boundary (cf. (16) above), as is the case for other NPs in Shingazidja (see \$4.1).

The constraint hierarchy in (44) accounts for the RA data, as exemplified in (45), where the nominal apposition is in object position.

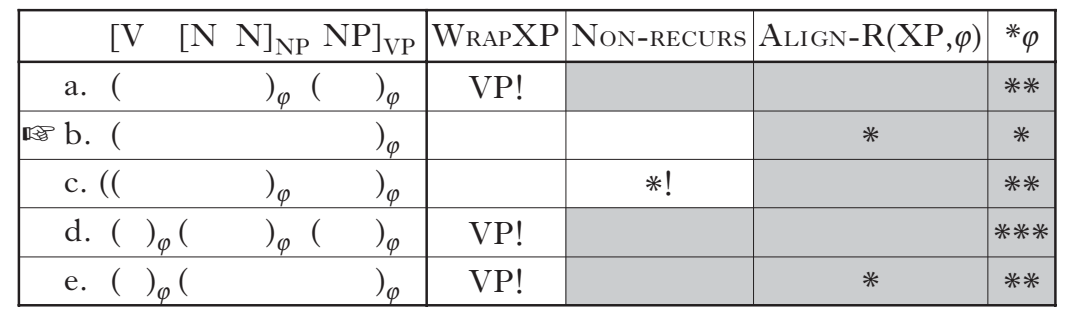

(45) shows that the RA facts and the analysis of Patin (2007) are perfectly compatible. In the next section, we test the Align/Wrap account against the data from NRAs, extending it to intonational phrasing.

5.1.3 Non-restrictive apposition. Here we present an OT analysis of NRAs. As claimed in $\$ 4$, NRAs require the alignment of their syntactic edges with $\imath$ boundaries. As opposed to $\varphi$ 's, $l$ 's in Shingazidja have received little attention, and neither Cassimjee \& Kisseberth (1998) nor Patin (2007) provide a formal analysis of their distribution. In Align/Wrap theory, the alignment of the $\mathrm{CP}$ and the $l$ is captured using the constraints in (46).

(46) a. Align-R(CP, $\imath$ )

The right edge of a CP must coincide with the right edge of an $\imath$ (based on Truckenbrodt 2005).

b. Align-L(CP, $\imath$ )

The left edge of a CP must coincide with the left edge of an $l$ (based on Feldhausen 2010).

The evidence from NRAs indicate that ALIGN-R(CP, $\imath)$ is high-ranked. As demonstrated in $\$ 4$, the right edges of NRAs are associated with final raising, and thus with the right edge of an $l$ in our analysis. However, as explained in $\$ 4$, direct evidence in favour of the presence of the left edge of a CP at the left edges of an $l$ is weaker. Nevertheless, the high frequency of occurrence of pauses before NRAs leads us to assume that Align-R(CP, $\imath$ ) is also high-ranked.

We argued in $\$ 4$ for recursivity in the intonational phrasing of NRAs: we consider the $t$ associated with the NRA to be embedded in a larger $t$. To 


\section{Kathleen M. O’Connor and Cédric Patin}

select the correct output, the constraint WRAPCP, formulated in (47), must dominate the alignment constraints in the hierarchy.

(47) WrapCP

Each CP is contained in a single $\iota$ (based on Truckenbrodt 2005: 286).

The three constraints in (46) and (47) must dominate Non-RECURSIVITY, as in (48) - for purposes of clarity, $\varphi$ boundaries are not indicated.

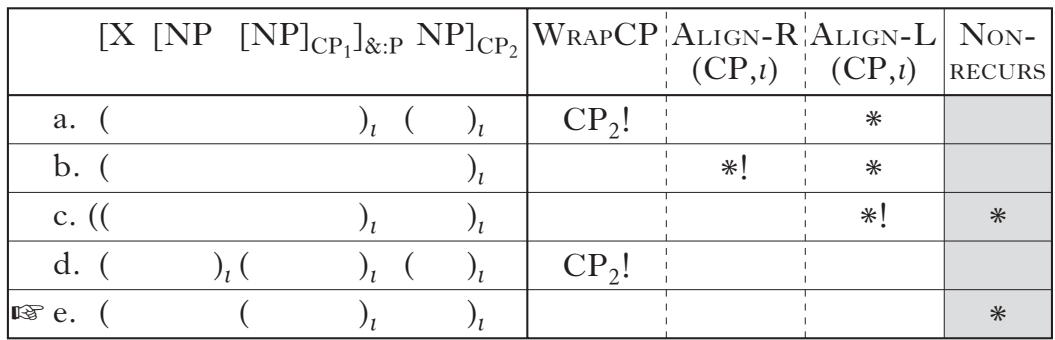

Candidates (b) and (c) are eliminated because they violate the highranked CP-alignment constraints. Candidate (e), although it violates Non-RECursivity, is preferred to (a) and (d), which violate WrapCP.

The new - nearly complete - hierarchy is presented in (49).

(49) WrapXP, Align-R(CP, $\imath)$, Align-L $(\mathrm{CP}, \imath) \gg \mathrm{WrapXP} \gg$ Non-Recursivity $\gg$ Align-R(XP, $\varphi)$

A final point should be made. Recall that in some integration analyses the NRA is the complement of a functional head, such as $\&:^{\circ}$, whose Spec hosts the anchor, and that an NRA may be selected as a complement by a verb, as in (22). Since the whole VP is included in a $\varphi$, as illustrated in (4) and demonstrated in (36), one might wonder how the phrasing of the NRA interacts with the phrasing of the VP to which it belongs. In the Align/Wrap framework, this issue is resolved using a constraint on prosodic domination, presented in (50).

LAYEREDNESS

No $\mathrm{C}^{i}$ dominates a $\mathrm{C}^{j}, j>i$, e.g. 'No $\sigma$ dominates a Foot' (Selkirk 1995: 466).

Selkirk (1995: 443) specifies: 'Layeredness and Headedness, which together embody the essence of the Strict Layer Hierarchy, appear to be properties that hold universally, in all phonological representations. In optimality theoretic terms the inviolability of these constraints implies that they are undominated in the constraint ranking of every language'. 
One consequence of the inviolability of LAYEREDNESs is that the words surrounding the NRA will belong to distinct $\varphi$ 's, even if they belong to the same syntactic phrase. Consider the simplified structure in (51a), and the possible prosodic structures in (b) and (c).

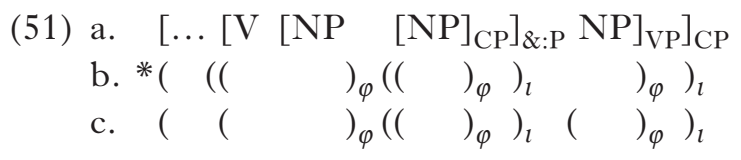

The structure in (b), where the $t$ associated with the NRA is included in the $\varphi$ associated with the VP, should be impossible due to the inviolability of LAYEREDNESs. As a consequence, a prosodic structure such as (c), in which no $\varphi$ includes all the words in the VP, is preferred. Note that we are currently unable to verify this prediction, since we are not aware of any prosodic properties that would distinguish (b) and (c).

\subsection{Match theory}

In this section, we propose an alternative account, couched within Match theory rather than Align/Wrap theory. In §5.2, we analyse NRAs in Match theory, and show that it offers a more economical account of the data. We then discuss the consequences for our analysis of phonological phrasing in Shingazidja, showing in particular that Match theory predicts additional $\varphi$ 's, and examining an additional tone rule that provides evidence for their existence.

Match theory was developed as an alternative to Align/Wrap theory (Selkirk 2009, 2011, Elfner 2012). It differs from Align/Wrap in that its constraints call for strict correspondence between syntactic and prosodic constituents, such that both edges of the former have to match both edges of the latter, and vice versa. In other words, syntactic and prosodic constituents are predicted to be isomorphic in Match theory, while Align/Wrap theory treats the alignments of left edges and right edges separately.

5.2.1 NRAs. To account for NRAs in Shingazidja, the Align/Wrap analysis relies on the three constraints in (46) and (47): Align-R(CP, $\imath$ ), Align$\mathrm{L}(\mathrm{CP}, \imath)$ and WraPCP. An account of the same data in Match theory requires only the constraint MatchClause in (52), from Selkirk (2011).

\section{(52) MatchClause}

A clause in syntactic constituent structure must be matched by a corresponding prosodic constituent, call it $l$, in phonological representation.

Compare for instance the tableau in (48) with the Match-theory tableau in (53). 


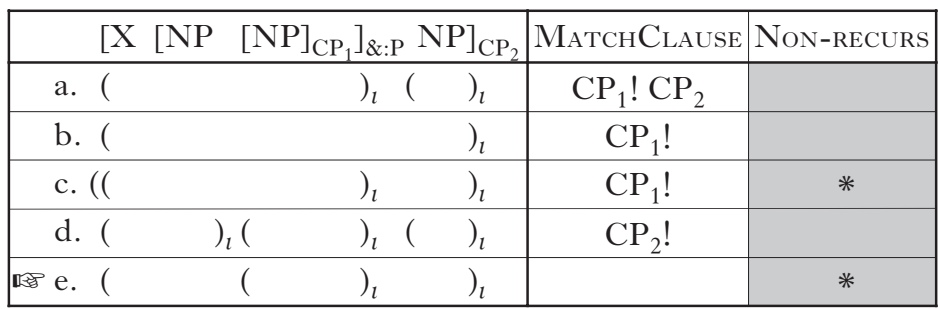

Candidates (a) and (c) are eliminated because the NRA does not correspond to an $t$. (d) is eliminated because $\mathrm{CP}_{2}$ does not correspond to an $t$. (b) is not optimal since it lacks an $t$ corresponding to $\mathrm{CP}_{1}$. (e), which is perfectly isomorphic with the syntactic structure, including its recursive aspects, is thus selected.

Consequently, Match theory provides a simpler account of our NRA data than Align/Wrap theory. Furthermore, the Match-theory account makes better empirical predictions: the model predicts that prosodic constituency will mirror syntactic constituency, including recursivity.

5.2.2 Consequences of Match theory for RAs. We now discuss the consequences of Match theory for the analysis of prosodic structure below the $\imath$ level. As a complete analysis of $\varphi$ 's in Match theory would require a separate study, we restrict ourselves here to a brief sketch.

Recall from $\S 3$ and $\$ 4$ that RAs, as NPs, behave like other NPs in the language: within the VP, they are neither preceded nor followed by $\varphi$ boundaries. Match theory, however, requires any syntactic phrase to correspond to a $\varphi$, under the influence of the constraint MatchPhrase in (54).

\section{(54) MatchPhrase}

A phrase in syntactic constituent structure must be matched by a corresponding prosodic constituent, call it $\varphi$, in phonological representation.

Consider the syntactic structure in (55a), where the second NP is an RA. The prosodic structure predicted by Match theory is given in (b), and the observed prosodic structure based on tone shifts in (c).
a. syntax

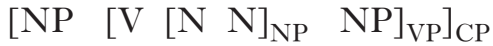
b. MatchPhrase prediction
$\left((\mathrm{NP})\left(\mathrm{V}(\mathrm{N} \mathrm{N})_{\varphi}\right.\right.$
$\left.\left.(\mathrm{NP})_{\varphi}\right)_{\varphi}\right)_{l}$
c. observed data
$\left((\mathrm{NP})\left(\begin{array}{llll}\mathrm{V} & \mathrm{N} & \mathrm{N} & \mathrm{NP}\end{array}\right)_{\varphi}\right)_{l}$

The two complements of the verb in (55b) are in different $\varphi$ 's. This seems to contradict the tone patterns discussed in $\$ 2$ and $\$ 4.1$. Recall that a tone can shift to an RA (or any other XP), or from an RA to a following phrase. Consequently, Match theory appears unable to account for the prosodic structure of Shingazidja below the $\imath$ level. 
It is possible, however, to reconcile Match theory and the behaviour of $\varphi$ 's by building on a proposal in Ito \& Mester, which they claim can be seen as complementing Match theory (2013: 23). ${ }^{12}$ They distinguish the MAXIMAL PROJECTION of a prosodic category $\alpha$, where $\alpha$ is not dominated by any other $\alpha$, from its MINIMAL PROJECTION, where $\alpha$ does not dominate any other $\alpha .{ }^{13}$ Crucially, domain-sensitive processes can target minimal or maximal projections. Applying this analysis to (55a) results in the prosodic structure in (56).

$$
\left((\mathrm{NP})_{\varphi_{\max }}\left(\mathrm{V}(\mathrm{N} \mathrm{N})_{\varphi_{\min }}(\mathrm{NP})_{\varphi_{\min }}\right)_{\varphi_{\max }}\right)_{l}
$$

We assume that the tone shift is sensitive to the edges of a Major Phrase $(\mathrm{MaP})$, in that a tone cannot shift from one Major Phrase to another, whereas it can cross the edges of a Minor Phrase (MiP). The shift of the tone across the boundaries of Minor Phrases can be accounted for using the family of CRISPEDGE constraints (Itô \& Mester 1994, 1999, Kawahara 2008, Selkirk 2011), which are violated by the linking of features across the edges of prosodic constituents. Using the domain-based account of tone shift in Cassimjee \& Kisseberth (1998) and Patin (2007), we analyse tone shift in Shingazidja by ranking the constraints that govern tone shift above a constraint CRISPEDGE(MiP, HD), which prevents a high-tone domain (HD) from crossing the boundaries of Minor Phrases, as shown in (57) (where, following Cassimjee \& Kisseberth, the high-tone domains are indicated by square brackets, and 'TONESHIFT' denotes the set of alignment constraints that interact to account for the movement of tones in the language; see Cassimjee \& Kisseberth 1998 and Patin 2007 for a fuller account of these constraints).

$$
\begin{aligned}
& \text { a. 'ToneShift' } \gg \text { CrispEdge(MiP, HD) } \\
& \sigma\left[\sigma \sigma \sigma_{\varphi_{\min }}(\sigma \sigma \sigma]_{\mathrm{HD}} \sigma\right. \\
& \text { b. CrispEdge(MiP, HD) } \gg \text { 'ToneShift' } \\
& \sigma[\sigma \sigma \sigma]_{\mathrm{HD} \varphi_{\min }}(\sigma \sigma \sigma \sigma \\
& * \sigma\left[\sigma \sigma \sigma_{\varphi_{\min }}(\sigma \sigma \sigma]_{\mathrm{HD}} \sigma\right.
\end{aligned}
$$

It might be objected that this analysis does not crucially differ from one using the constraint WRAPXP (see §5.1), and that it merely consists of an ad hoc technical solution to the problem sketched at the beginning of this section. There is, however, a crucial difference between an Align/Wrap analysis with high-ranked WRAPXP and the Match-theory account here: the latter account predicts the systematic presence of recursivity in phonological phrasing in the case of a nested syntactic phrase, such as a VP with NP arguments in Shingazidja. Independent evidence in favour of a lower

12 We are grateful to Lisa Selkirk for suggesting this analysis to us.

13 We do not have space here to expand on the analysis. 


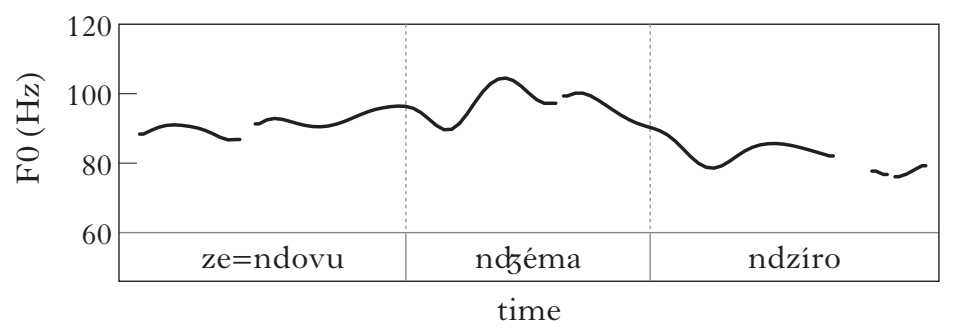

Figure 9

F0 contour for the sentence in (58).

level of phonological phrasing (as Minor Phrases) would thus constitute a strong argument in favour of our analysis.

Such an argument does, in fact, exist. When a word lacking an underlying tone is realised in isolation, it receives a surface tone on its penult (Philippson 2005, Patin 2007), e.g. /N-dovu/ $\rightarrow$ [n-dóvu] 'elephant(s)'. This rule, which we call Surface Tone Insertion, also applies to the penult of a phrase in isolation consisting of two toneless words, e.g. /N-dovu N-dziro/ $\rightarrow$ [n-dovu n-dzíro] 'heavy elephant(s)' (see Philippson 2005: 204).

In the dialect of Moroni, moreover, we find multiple insertions of a surface tone in contexts like that in (58), where both post-nominal adjectives bear an inserted tone (cf. Fig. 9). ${ }^{14}$ Note that the inserted tone does not shift rightwards, indicating that it is different from the lexical tones discussed previously. ${ }^{15}$

$$
\begin{aligned}
& \text { /ze }=\mathrm{N} \text {-dovu N-dzema N-dziro/ } \\
& \text { 10.AUG }=10 \text {-elephant } 10 \text {-nice 10-heavy } \\
& \text { ze }=\text { ndovu ndzéma ndzíro } \\
& \text { 'the nice heavy elephants' }
\end{aligned}
$$

This phrase-medial appearance of the surface tone on /N-dzema/ in (58) is unexpected, except if the [N A A] construction is syntactically analysed as the quite plausible nested syntactic phrase structure in (59), corresponding to the recursive $\varphi$ structure, in accordance with MATchPHRASE (Selkirk 2011).

14 This form of the rule does not seem to exist in other dialects. Our speakers from the North (from Mbeni), for instance, realised sentence (58) without the tone on the word /ndzema/: [ze=ndovu ndzema ndzíro].

15 This parameter indicates that the rule differs from another tone-insertion rule described in Cassimjee \& Kisseberth (1989), which we call Lexical Tone Insertion, where the inserted tone has the same properties as any other lexical tone (i.e. it can shift and delete any other tone). The latter rule also exists in the Moroni dialect (Patin 2010). 
What the distribution of Surface Tone Insertion would reveal, then, is the very presence of $\varphi$ 's, at whatever level: it inserts a surface high tone on the penult syllable of a Minor Phrase in the case of / N-dzema/ and on the penult of a higher level of $\varphi$ in the case of the second adjective /N-dziro/. The context of Surface Tone Insertion would simply be 'penult of $\varphi$ ', i.e. any $\varphi$. Note that the Align/Wrap account discussed in $\$ 5.1$ also has to deal with the tones that are inserted by Surface Tone Insertion, i.e. with the existence of recursive $\varphi$ in Shingazidja (at least in the Moroni dialect). The difference between the two approaches is that Match theory predicts the systematic presence of recursive $\varphi$ structure, while Align/Wrap theory does not. Alongside the fact that Match theory provides a simpler account of the NRA data than Align/Wrap theory, the facts regarding recursive $\varphi$ lead us to prefer the Match analysis of apposition in Shingazidja.

It should be noted in concluding, however, that the above analysis does not account for all patterns of phrasing in Shingazidja. First, neither Align/Wrap nor Match theory can currently account for the prosodic behaviour of the augment (see \$2). Second, the general presence of recursive phonological phrasing advocated for here constitutes a major problem for the account of the focus cases discussed in $\$ 5.1$, which assumed that $\varphi$ recursion was unique to the cases of focus in Shingazidja. ${ }^{16}$ Further research is required to resolve these issues.

\subsection{Summary}

In the preceding sections, we developed an OT analysis of the prosody of apposition in Shingazidja. In $\$ 5.1$, we developed an Align/Wrap analysis of the data. We first showed that the Align/Wrap analysis developed in Patin (2007) can be extended to RAs. To account for NRAs, we used constraints that align the clause with an $\imath$ boundary.

In $\$ 5.2$, we proposed an alternative OT analysis of the data in Match theory. We showed in \$5.2.1 that Match theory accounts for the prosodic behaviour of NRAs in a more economical way than Align/Wrap theory. In $\$ 5.2 .2$, we discussed the consequences of a MatchPHRAse analysis of our data for $\varphi$ 's. We observed that Match theory predicts the existence of additional $\varphi$ 's beyond those maximal $\varphi$ 's which form the domain for tone shift, and we provided an argument from Surface Tone Insertion in favour of their existence. We discuss below the significance of our account and directions for future research.

16 The main issue is that the Focus $\varphi$, which is sister to two other $\varphi$ 's in the structure [V NP NP], behaves like a Major Phrase. Given the definition of Major Phrase in Ito \& Mester's work (i.e. any sister of $\varphi_{\max }$ should be a $\varphi_{\max }$ itself, if the notion $\varphi_{\max }$ is defined in terms of dominance relations), this should not be possible. A solution to this problem may lie in an improved understanding of how prosodic subcategories are defined, which will be explored in future work. We thank an anonymous reviewer and Lisa Selkirk for drawing this problem to our attention. 


\section{Kathleen M. O’Connor and Cédric Patin}

\section{Conclusion}

Our analysis has touched on many issues that are relevant to syntax and prosody and their interface. We will take the opportunity in this section to consider some of these, and to outline directions for future research.

First, we outlined a major issue in the syntax of apposition: the syntactic relationship between an appositive and its host clause. Whereas the analysis of restrictive apposition as a single NP is rather straightforward, the analysis of NRAs is more controversial. We considered two analyses. In an orphanage approach, there is assumed to be no syntactic link between the appositive and its host clause, while in an integration analysis, a syntactic link of some kind is posited. The ambiguous syntactic behaviour of the appositive does not argue in favour of either analysis.

The prosodic evidence, however, clearly argues for an integration analysis. As noted in $\$ 4$, NRAs occur in a recursive structure in which the $l$ of the NRA is embedded inside the $l$ of the host clause, rather than in a separate $l$. This suggests a syntactic link between the two parts. If there were no such link, recursivity would be unexpected.

It is not possible to argue for one integration analysis over another. We uncovered similarities in phrasing between NRAs and coordinated clauses, which may constitute evidence for a coordination analysis. As the initial results here are promising, one direction for future research is to compare in more detail the prosodic behaviour of NRAs with that of other clausal elements in an attempt to discern the proper integration analysis. In addition to looking closely at coordinated causes, it would be particularly important to examine other types of non-restrictive modifiers, e.g. absolutes and adverbial clauses.

It would, of course, be interesting to test these conclusions on other languages. Though there is considerable syntactic literature on apposition in English, there has, to our knowledge, been no systematic examination of the syntax-prosody interface. The analysis could also be tested with other parenthetical or non-restrictive structures.

Our analysis is also significant in that it is the first specifically devoted to apposition in a Bantu language. Not only have we examined the syntactic characteristics of the structure, but we have also considered the syntaxprosody interface, thus making a contribution to the larger body of literature on Shingazidja in particular and on Bantu more generally.

Overall, the data enrich our knowledge of the phrasing and syntax of Shingazidja and Bantu languages as a whole. As noted by Zerbian (2006: $130)$, 'there is no consensus' among Bantu scholars about the number or types of prosodic levels above the prosodic word. In $\$ 4$, we provided arguments in favour of the existence of intonational phrases, alongside phonological phrases, in Shingazidja. Clearly, more work will be needed to further test, extend and refine our conclusions.

The apposition data are also useful because they provide a testing ground for a comparison of competing approaches to the syntax-phonology interface in OT. The data on apposition allowed us to compare the Align/Wrap and 
Match theories of the syntactic structure-prosodic structure relation. Though both approaches provide adequate descriptions of the data, the Match analysis has two advantages. First, it is more economical. Second, it predicts the existence of recursive phonological phrasing in Shingazidja, which is confirmed by independent evidence.

Although the Match analysis is promising, we would like to find more evidence concerning the left edges of prosodic groups in order to further test and refine the analysis. Moreover, apposition constitutes one type of syntactic structure. It would certainly be worthwhile to construct a Match analysis of a wider range of phenomena in order to test the theory more fully.

For NRAs, the data reveal that final raising, as opposed to non-finality, should be taken as the main indicator of an $t$. This conclusion remains to be tested with other speakers on a wider variety of examples. Moreover, it could also be tested on a broader array of syntactic structures, such as dislocations and focused phrases.

The above issues thus provide a rich array of possibilities for future research in several domains. The continuing study of syntax, prosody and their interface, both in Bantu and in other languages, is predicted to contribute a great deal to our understanding of apposition and other syntactic structures.

\section{REFERENCES}

Acuña-Fariña, Juan Carlos (1996). The puzzle of apposition: on so-called appositive structures in English. Santiago de Compostela: Universidade, Servicio de Santiago de Compostela.

Acuña-Fariña, Juan Carlos (1999). On apposition. English Language and Linguistics 3. $59-81$.

Beckman, Mary E. \& Janet B. Pierrehumbert (1986). Intonational structure in Japanese and English. Phonology Yearbook 3. 255-309.

Burton-Roberts, N. (1975). Nominal apposition. Foundations of Language 13. 391-419.

Cassimjee, Farida \& Charles W. Kisseberth (1989). Shingazidja nominal accent. Studies in the Linguistic Sciences 19. 33-61.

Cassimjee, Farida \& Charles W. Kisseberth (1992). Metrical structure in Shingazidja. CLS 28. 72-93.

Cassimjee, Farida \& Charles W. Kisseberth (1993). The phrasal tonology of Shingazidja. Paper presented at the 24th Annual Conference on African Linguistics, Ohio State University.

Cassimjee, Farida \& Charles W. Kisseberth (1998). Optimality Domains Theory and Bantu tonology: a case study from Isixhosa and Shingazidja. In Larry M. Hyman \& Charles W. Kisseberth (eds.) Theoretical aspects of Bantu tone. Stanford: CSLI. 33-132.

Cheng, Lisa \& Laura J. Downing (2007). The phonology and syntax of relative clauses in Zulu. SOAS Working Papers in Linguistics and Phonetics 15. 51-63.

Del Gobbo, Francesca (2003). Appositives at the interface. PhD dissertation, University of California, Irvine.

Doron, Edit (1992). Appositive predicates. Belgian Fournal of Linguistics 7. 23-33.

Elfner, Emily (2012). Syntax-prosody interactions in Irish. PhD dissertation, University of Massachusetts Amherst. 


\section{Kathleen M. O’Connor and Cédric Patin}

Feldhausen, Ingo (2010). Sentential form and prosodic structure of Catalan. Amsterdam $\&$ Philadelphia: Benjamins.

Heringa, Herman (2011). Appositional constructions. PhD dissertation, University of Groningen.

Itô, Junko \& Armin Mester (1994). Reflections on CodaCond and Alignment. In Jason Merchant, Jaye Padgett \& Rachel Walker (eds.) Phonology at Santa Cruz 3. Santa Cruz: Linguistics Research Center. 27-46.

Itô, Junko \& Armin Mester (1999). Realignment. In In René Kager, Harry van der Hulst \& Wim Zonneveld (eds.) The prosody-morphology interface. Cambridge: Cambridge University Press. 188-217.

Ito, Junko \& Armin Mester (2013). Prosodic subcategories in Japanese. Lingua 124. $20-40$.

Kanerva, Jonni M. (1990). Focus and phrasing in Chichewa phonology. New York: Garland.

Kawahara, Shigeto (2008). On the proper treatment of non-crisp-edges. In Mutsuko Endo Hudson, Sun-Ah Jun, Peter Sells, Patricia M. Clancy \& Shoichi Iwasaki (eds.) Fapanese/Korean linguistics. Vol. 13. Stanford: CSLI. 55-67.

Kayne, Richard S. (1994). The antisymmetry of syntax. Cambridge, Mass.: MIT Press.

Keizer, Evelien (2007). The English noun phrase: the nature of linguistic categorization. Cambridge: Cambridge University Press.

McCawley, James D. (1995). An overview of 'appositive' constructions in English. Proceedings of the Eastern States Conference on Linguistics 12. 195-211.

O'Connor, Kathleen M. (2008). Aspects de la syntaxe et de l'interprétation de l'apposition à antécédent nominal. $\mathrm{PhD}$ dissertation, Université Charles-de-Gaulle, Lille 3.

Odden, David (1990). Tone in the Makonde dialects: Chimarba. Studies in African Linguistics 21:1. 61-105.

Patin, Cédric (2007). La tonologie du shingazidja, langue bantu (G44a) de la Grande Comore: nature, formalisation, interfaces. $\mathrm{PhD}$ dissertation, Université Paris 3.

Patin, Cédric (2010). The prosody of Shingazidja relatives. ZAS Papers in Linguistics 53. $187-210$.

Philippson, Gérard (1988). L'accentuation du comorien: essai d'analyse métrique. Études Océan Indien 9. 35-79.

Philippson, Gérard (2005). Pitch accent in Comorian and Proto-Sabaki tones. In Koen Bostoen \& Jacky Maniacky (eds.) Studies in African comparative linguistics, with special focus on Bantu and Mande: essays in honour of Yvonne Bastin and Claire Grégoire. Tervuren: Musée Royal de l'Afrique Centrale. 199-220.

Potts, Christopher (2005). The logic of conventional implicatures. Oxford \& New York: Oxford University Press.

Quirk, Randolph, Sidney Greenbaum, Geoffrey Leech \& Jan Svartvik (1985). A comprehensive grammar of the English language. London \& New York: Longman.

Rizzi, Luigi (1997). The fine structure of the left periphery. In Liliane Haegeman (ed.) Elements of grammar. Dordrecht: Kluwer. 281-337.

Ross, John R. (1967). Constraints on variables in syntax. PhD dissertation, MIT.

Samek-Lodovici, Vieri (2005). Prosody-syntax interaction in the expression of focus. NLLT 23. 687-755.

Selkirk, Elisabeth (1986). On derived domains in sentence phonology. Phonology Yearbook 3. 371-405.

Selkirk, Elisabeth (1995). The prosodic structure of function words. In Jill N. Beckman, Laura Walsh Dickey \& Suzanne Urbanczyk (eds.) Papers in Optimality Theory. Amherst: GLSA. 439-469.

Selkirk, Elisabeth (2000). The interaction of constraints on prosodic phrasing. In Merle Horne (ed.) Prosody: theory and experiment. Studies presented to Gösta Bruce. Dordrecht: Kluwer. 231-261. 
The syntax and prosody of apposition in Shingazidja 145

Selkirk, Elisabeth (2009). On clause and intonational phrase in Japanese: the syntactic grounding of prosodic constituent structure. Gengo Kenkyu 136. 35-73.

Selkirk, Elisabeth (2011). The syntax-phonology interface. In John A. Goldsmith, Jason Riggle \& Alan C. L. Yu (eds.) The handbook of phonological theory. 2nd edn. Oxford: Wiley-Blackwell. 435-484.

Toribio, Almeida Jacqueline (1992). Proper government in Spanish subject relativization. Probus 4. 291-304.

Truckenbrodt, Hubert (1995). Phonological phrases: their relation to syntax, focus, and prominence. $\mathrm{PhD}$ dissertation, MIT.

Truckenbrodt, Hubert (1999). On the relation between syntactic phrases and phonological phrases. LI 30. 219-255.

Truckenbrodt, Hubert (2005). A short report on intonation phrase boundaries in German. Linguistische Berichte 203. 273-296.

Truckenbrodt, Hubert (2007). The syntax-phonology interface. In Paul de Lacy (ed.) The Cambridge handbook of phonology. Cambridge: Cambridge University Press. 435-456.

Tucker, A. N. \& M. A. Bryan (1970). Tonal classification of nouns in Ngazija. African Language Studies 11. 351-382.

Van de Velde, Mark (2013). The Bantu connective construction. In Anne Carlier \& Jean-Christophe Verstraete (eds.) The genitive. Amsterdam \& Philadelphia: Benjamins. 217-252.

Vries, Mark de (2006). The syntax of appositive relativization: on specifying coordination, false free relatives, and promotion. LI 37. 229-270.

Zerbian, Sabine (2006). Expression of information structure in the Bantu language Northern Sotho. PhD dissertation, Humboldt University, Berlin. 